\title{
THEORETICAL AND METHODOLOGICAL PRINCIPLES FOR ASSESSMENT THE READINESS OF SOCIO-ECONOMIC SYSTEMS FOR CHANGES
}

\author{
Anatolii Mazaraki', Yuliya Drozdova², Sergey Bay
}

\begin{abstract}
The article is devoted to theoretical and methodological problems of assessing the readiness of socioeconomic systems for changes. The theories of factors that are the mainstay of this study are the interesting section in this study. To complete the study of changes in complex socio-economic systems, along with the approaches of evolutionary universalism, a set of scientific methods was applied, namely: structural-functional analysis, comparative-typological analysis, historical method, methods of induction and deduction. The aim of the article. The main purpose of the study is to develop further theoretical and methodological approaches to scientific substantiation of changes in socio-economic systems in different concepts of evolutionary economics. Methodology. The methodological and theoretical foundations of the research are the theories of factors that are the mainstay of this study. To complete the study of changes in complex socio-economic systems, along with the approaches of evolutionary universalism, a set of scientific methods was applied, namely: structural-functional analysis, comparative-typological analysis, historical method, methods of induction and deduction. Value/ originality. In particular, we defined methodological requirements for the evaluation process and systematized the formalized methods of different levels of socio-economic systems assessment implementation complexity. We proved scientifically that the trajectory of system movement is determined by achievement a critical point that changes the quality of socio-economic system. At the same time, the value capitalization of the enterprise should be ensured concerning consumers and other stakeholders, participants of the enterprise activity. The levels of socio-economic system readiness for changes are highlighted.
\end{abstract}

Key words: socio-economic systems, enterprise, evaluation process, changes.

JEL Classification: F63, O11, O10

\section{Introduction}

Recently the prospect of changes in socio-economic systems study is indisputable because, under the conditions of increasing economic fluctuations, complex systems take on qualitatively new forms (temporal, spatial, dynamic), change their behavior, and require effective theoretical and methodological tools. According to this thesis scientific frames of changes in socio-economic systems are recognized as a modernist vector for the development of modern economic science and at the same time an applied tool for managing their organizational complexity, devoid of abstract scientific images, and as close as possible to real conditions of economy functioning.

Modern enterprises, as socio-economic systems, constantly operate under the conditions of limited resources: raw materials, time, finances, information, etc. Increasing relationship inside and outside the enterprise extends its freedoms and capabilities, increases the interdependence of all parts and elements in the enterprise, accumulation of organizational complexity at all levels and in all spheres of human activity through a combination of "globally ubiquitous factors" - "changes acceleration in growing uncertainty"(Prigogin, 2007). As a result, the entropy increases, and there is an increase in the "substance of enterprise" composed of new nature elements. It is increasingly difficult for executives and managers to orient under such conditions: there are tendencies for disorganization and reduction (or even lose) of controllability.

Under these conditions, we can observe "Fair reassessment of values, which describe what exactly

\footnotetext{
Corresponding author:

${ }^{1}$ Kyiv National University of Trade and Economics, Ukraine.

E-mail: rector@knute.edu.ua

${ }^{2}$ Kyiv National University of Trade and Economics, Ukraine.

E-mail: fast777@bigmir.net

${ }^{3}$ Kyiv National University of Trade and Economics, Ukraine.

E-mail: s.bay@knute.edu.ua
} 
economic agents do as they learn and interact, good faith reassessment of principles that describe what exactly economic entities do, how they learn and interact" (Dosi, Winter, 2003). Therefore, the consolidation of different views on the internal structure and environment of the enterprise is a very urgent task. Naturally, in recent years, studies of internal organizational content are again becoming a priority for both evolutionary, institutional, and management theories.

\section{Recent research and publications review}

A critical review of scientific research in the context of changes in socio-economic systems including the problems of their theoretical and methodological support made possible to highlight a strong scientific and practical basis formed in the papers of Hurwicz (1996), Dosi, Winter (2003), Kleiner (2002, 2003), Rakhaev (2006), Izmalkov, Sonin, Yudkevich (2008) and others.

Despite the renewed scientific interest to socioeconomic systems, problems of their functioning, in theory and practice, there is a somewhat fragmentary analysis and a selective approach to highlight some aspects of their changes and transformations. As a result, there is an objective need to develop new theoretical generalization approaches to solving the problems of implementing changes in socio-economic systems of varying complexity in the context of their response to exogenous and endogenous challenges.

The main purpose of the study is to develop further theoretical and methodological approaches to scientific substantiation of changes in socio-economic systems in different concepts of evolutionary economics.

\section{Materials and methods}

The theoretical and methodological basis for the study were: scientific papers of national and foreign economists on the problems of changes in socio-economic systems. Thus, Bilotserkovets and Zavgorodnyastate (2003) wrote: "Dialectics, as the underlying theory and methodology of economic science development, ascends to the next level of specifics as a methodological paradigm of global (universal) changes". Hence, evolutionary universalism is perhaps the only approach in the scientific arsenal for modern researchers of complex socio-economic process changes, since its theories synthesize elements of the system, reveal their compatibility at the essential level and logical impartiality caused by common dialectical origin.

The the theories of factors that are the mainstay of this study are interesting in this section of study. To complete the study of changes in complex socio-economic systems, along with the approaches of evolutionary universalism, a set of scientific methods was applied, namely: structural-functional analysis, comparativetypological analysis, historical method, methods of induction and deduction.

\section{Results}

According to the theory of the factors, business entities spend resources that meet the following parameters: "certainty," "proper proportionality," "dependence" to obtain the necessary final results. Combining all the resources at the disposal of the business enterprise, or their "impersonation" to sole factors, allows to "formalize and quantify" economic processes at the level of direct economic entities with the output to forecasting and managing them. This is reflected in the production functions of various modifications (Koval, Slobodianiuk, Yankovyi, 2018).

Methodology and logic of many studies are based precisely on the active use of production function apparatus, which today is considered an adequate tool to study the behavior of organizations, their growth, and is also actively used for forecasting the economy as a whole (Shumska, 2007). Factors are traditional resources: labor, land, capital in their specific form of a real economic entity (Koval et al., 2019). Traditionally, the result is the amount of gross output produced by a specific entity over a certain time period, the structure of production, volume of income, level of productivity, etc. (Rakhaev et al., 2006).

The production function $Y=f(K, L, t)(\mathrm{PF})$ determines the relationship of the output of product $Y$ with the factors of production - capital $(K)$ and labor $(L)$, which may change over time $(t)$. The mechanism of structural shifts is more explicit in terms of traditional factors of economic development, especiallyhighlighting models of factor analysis of $\mathrm{R}$. Solow, which relies on the analysis of national savings determining role, population growth, and technological progress. It proceeds from a functional relationship between the amount of product, labor, and capital established by the American scientists Cobb and Douglas in the early twentieth century. The Cobb-Douglas production function $Y=A K^{a} L^{b}$ made it possible to lay the foundations of the process of direct labor substitution by materialized labor. Parameters $a$ and $b$ show the proportion in which capital and labor resources affect the output. In particular, as labor costs increase by $\mathrm{n}$, the same increase in product growth may occur, the same may occur with the increase in fixed capital. It was Cobb and Douglas who first obtained the formula: $Y=1,01 K^{0,25} L^{0,75}$.

In the Solow model, savings $(S)$, which are calculated as GDP minus consumption and public procurement, are at the forefront. From there: $Y=(1-S)+i$. Investment $(i)$, or capital accumulation, directly determine economic growth and structural policy preconditions. In fact, the accumulations indicate an increase in GDP resources, but it must be adjusted for 
capital outflows due to physical and moral deterioration. The change in the capital will be equal to the investment minus the disposal of capital. Optimal growth of capital accumulation determines the pace of economic and social progress of society (Bukanov et al., 2019).

Economic growth and development is achieved through growth in fixed capital, labor costs, and technological progress. However, the production function must satisfy certain conditions that have an economic interpretation:

- in the absence of one of the resources, production is impossible:

$$
f(0, L)=f(K, 0)=0 \text {; }
$$

- an increase in the costs of any resources with a constant amount of another leads to an increase in output over time:

$$
d f / d K>0, d f / d L>0
$$

- with an unlimited increase in one of the resources, the output increases over time:

$$
f(+\infty, L)=f(K,+\infty)=+\infty ;
$$

- as resources grow, the rate of output growth slows;

- keeping the output constant can be achieved by partially replacing one factor with the additional use of another;

- the function is homogeneous to the degree of $p(p>1)$. With the increase in production scale in $\mathrm{h}$ times the output increases in hp times, i.e. we have an increase in production efficiency due to its increase in scale;

- the function is continuous and twice differentiated by the arguments $K$ and $L$.

Adequate productive function representation of the real ratio of resource costs and output requires the selection of significant factors and definition of the type of function, as well as the parameterization of the production function, that is, the calculation of parameters quantitative values based on systematic statistics using regression and correlation analysis. The choice of factors allows meaningful interpretation of production function characteristics, which allows us to obtaine meaningful conclusions about the parameters of a production function, identifying periods that are characterized by different behavior of the output, identify turning points (transition boundaries), find out the process timeline.

Foreign scholars determine the relation between labor and capital on the basis of the concepts of marginal labor productivity and marginal productivity of capital, introduced into the economic analysis by the American economist J.B. Clark, developed by E. Denison, R. Solow, and others. However, this theory has received much criticism, particularly from the Cambridge School of Left Keynesianism, led by J. Robinson. In the 1993 system of national accounts, the theory of the factors is not available. Overall, economic development is achieved through growth in fixed capital, labor costs, and technological progress. International factors play a significant role, first of all, the balance of trade and the balance of payments, the exchange rate, purchasing power parities, and the proportions of international exchange that depend on them.

At the same time, the factor model does not provide a clear answer regarding the financial resources of the structural adjustment. It exogenously states that investment and other resources are available. They just need to be used properly. It should be borne in mind that the enterprise becomes "the only place where the combination of labor, items of labor, production, and labor for the production of products" are combined in a "single holistic object." According to G.Kleiner, the definition of factors that "determine the behavior of the enterprise in various areas of its operation" and "establishing a dominant in decision-making and implementation" (Kleiner, 2003) are central to the construction of an "individualized theory".

Each of the enterprise activity participants in a certain way has own vision, puts forward expectations and requirements, that are the descriptive and normative components of the perception and systematic description of the enterprise for each of them will have a personalized interpretation. Despite the fact that, as noted by Nobel Prize winner J. Heckman, micromodels are not very diverse and are sufficiently stable (Eliseeva, Dmitriev, 2003).

Discussions on factors of production allowed us to introduce the notion of production dependence, we can use not only absolute but also relative quantities, as well as a large selection of production factors (Kleiner, 2002), which must satisfy some logical, economic, and mathematical requirements:

- all quantities included in the production function must be measured;

- production without resource costs is impossible;

- all resources included in the production function are required, in the absence of at least one of them, production being zero;

- the arguments of the production function must include all the factors relevant to the production process (the condition is ambiguous);

- the resources are interchangeable in one way or another (they may be complementary, that is, in strictly defined proportions);

- if the volume of a resource is limited, then the output cannot increase indefinitely;

- all quantities should have a clear economic meaning;

- the production function should be based on the appropriate statistical base;

- the production function must be continuous and differentiated (Tereshchenko, 2008).

In the modern world, a system-wide combination must be perceived in a one-to-one measurement and evaluation system. Nevertheless, understanding the behavior of business entities as probabilistic rather than deterministic 
must be dominant. There is a definite relationship between the results of the enterprise's activities and the factors (resources) at its disposal that must be calculated, evaluated, and described. This leads to the transition from the evaluation and description of organizations' behavior by methods of probability theory to the paradigm of nonlinear dynamics (Bessonov, 2000).

Use of this approach allows us to distinguish the main components of the description as fundamentally "static" and "kinetic" features of changing the enterprise parameters, and functioning of the enterprise as a whole, and not any of its subsystems (Gontareva, 1975). These are ascending conceptual positions form the "archetype" of enterprise perception. The establishment of boundaries between the enterprise and the external environment, justification of the mechanism for establishing relations between the intentional (target) sphere of the enterprise, and the mode of operation may be particularly important in this regard. Believing in the internal organizational processes from these positions, in our opinion, makes it possible to call them the "rules of the game for all occasions," which will guarantee the result expected by the "bona fide maker of the mechanism" every time (Rakhaev, 2006).

In the age of the information revolution, the organizational mechanism is an extremely complex system involving several groups of relationships. Because of this, the mechanism itself is the source of the institutional content of the enterprise, a set of relatively stable norms, traditions, and patterns of behavior that are unique to it. The multidimensionality of the organizational mechanism as a complex system, represented by various relationships, causes the formation of a particular structure and some entities through which these relationships manifest themselves. The organizational mechanism is a component of a more complex, social mechanism. As for the enterprise, it characterizes the expedient set of relationships within the production and management processes, all other phenomena within which the production mechanism and management mechanism are implemented.

In this regard, it is more correct to speak of a "family of economic mechanisms than of a specific mechanism" (Izmalkov et al., 2008). They form unique institutional space that structures the subjects' rules of conduct, their strategies, management decisions, and performance. In general, this set of interconnections between all elements of organizational relations determines the dynamic state of the management system, which determines the degree of its mobility, susceptibility to changing conditions.

Particular importance gets the formation of such an economic mechanism, which should provide extended reproduction, and allow the development of each economic entity - because the organizational form of the business itself is not decisive for the development of production and efficiency increase. Furthermore, in cases where its "implementation is impossible or linked to prohibited costs, even the most attractive mechanism," says Nobel laureate L. Hurwitz, "remains a utopia" (Hurwicz, 1996).

The key in the theory of economic mechanisms is the introduction into the scientific circulation of L. Hurwitz's concept of "conditions of inventive compatibility," which can reasonably be considered as "convenient interpretation of economic entities rationality assumption" (Tereshchenko, 2008).

The main organizational components of the mechanism are the structures that organize industrial relations, as well as tools for managerial influence on the future development of the system in order to develop directions for its improvement. As part of this approach, it is advisable to consider the policy of the enterprise, the economic component of which is focused on improving the efficiency of economic entities production due to a specific set of production realization principles and financial relations between the system links, as well as tools to achieve the parameters of economic efficiency. Thus, the main functions of the organizational and economic mechanism are:

- realization of the economic potential laid down in each enterprise;

- ensuring effective interaction between enterprises as economic entities and other institutional entities;

- self-realization and interaction of each economic activity type enterprises in order to ensure efficient organization of production in general;

- maintaining the compliance of economic behavior of enterprises concerning self-regulation of the economic system following the requirements for economic laws and resolution of socio-economic contradictions;

- maintaining a balance between the economic, organizational, legal, social, environmental areas that ensures the freedom and efficiency of development in general and full development of society and individual, their needs, interests, incentives in particular;

- balancing and harmonization of property forms relations realization.

At present, there is no single point of view regarding the uniqueness in defining the scheme or model of designing and building an enterprise to create the preconditions for real development. Changes in the economy require a revision of the theoretical basis for the search for new mechanisms of behavioral algorithms, which are adequate to the new schemes and models of enterprise management. The acquisition of new knowledge regarding the need to improve the system of real enterprise development through (including) reforming the mechanisms of functioning of economic systems is an integral attribute of ensuring strategic management success. That is, the experience of successful organizational transformation can only be limited to that used in other enterprises and in no way can be universal. 
In the management of events related to "taking down events" (Izmalkov et al., 2008), the so-called "cognitive parallax" (Ruley, 1998) leads to increasing uncertainty. Uncertainty will mean the absence, insufficiency, or inaccuracy of information about the state of the system and its environment (Ruegg-Sturm, 1998).

So, there is a need to use such a tool to evaluate the feasibility of conducting transformational activities within a trading enterprise, which would provide the highest efficiency regardless of the level of enterprise development, its format and scale of activity, as well as increase the importance of formation as a means of managing enterprise efficiency and capacity building of its development.

In order to be able to successfully achieve this goal, fulfill its functions in the market, maintain its competitive position, the company needs to achieve the necessary competence. The required scope and effectiveness of its implementation depend on the quality of the management system in terms of the ability to fully and adequately reproduce organizational competencies. Their functional value description can be expressed in monetary terms, and its variability will cover a certain value range $(M)$. Within this range, aggregate consumer value is accumulated, which may be adequate to the value of expected cash flow from the reproduction of organizational development potential per unit of resource consumption per time unit. The institutional function of enterprise reform can be expressed by the formula (Reut, 2003):

$$
T P_{i j}^{t}=F\left(\Delta Y_{i}, K_{i}, L_{i}, T_{i j}\right)
$$

$\Delta Y_{i}$ - an increase in organizational competence, which may be represented by:

$$
\Delta Y_{i}=F(S P, I K, I L, I N, F I N, Q)
$$

as a function of the harmonization of the operating structure $(S P)$; fixed assets (IR); labor force (IL); innovative behavior (IN); financial resources (FIN); quality management $\left(Q \cdot K_{i}(t)\right.$ - a function that describes the process of enterprise capitalization; $L_{i}(t)$ - function that describes the variability of human potential; $T_{i j}(t)$ - function of innovation and technological behavior.

According to the concept of economic dysfunction, an enterprise can only function steadily within the defined monetary range of the value range. The boundaries of the monetary range are entirely individual and can be defined for each enterprise. The decrease in the coefficient of return $B_{(t)}$ and the monetary provision of the value range causes the emergence of so-called opportunistic models of functioning and use of a specific resource, which can lead to an overall decrease in the utility of the whole enterprise, its dysfunction (microor macro-dysfunction) (Borisov, 1989).

Decreasing the impact of development potential as a specific resource will be perceived in practice by the management system as a temporary phenomenon, acquire a qualitative norm, and not be problematic under the law of inertia of behavior.
In the process of enterprise development, in particular, by generating a specific development resource, its organizational development potential should be increased. For the enterprise, this is the most successful stage when the potential for development $\left(\prod P_{i}^{t}\right)$ through new reproduction gets a new value $\left(\prod P_{i}^{t^{\prime}}\right)$ and creates the conditions for further increase of its competence. In the conditions of changing the performance of the activity, regardless of what caused it exogenous or endogenous, the actual monetary support for the functioning of the business enterprise increases/ decreases. The enterprise can increase/decrease its competence, i.e., it gains/loses the ability to service itself in the planned parameters.

The differential function $M_{i}(t)$ for the i-th enterprise will be:

$$
\begin{gathered}
d M_{i}=\left[a_{1} \frac{\partial M i}{\partial L i} \frac{\partial L i}{\partial t}+a_{2} \frac{\partial M i}{\partial K i} \frac{\partial K}{\partial t}+a_{3} \frac{\partial M i}{\partial T i} \frac{\partial T i}{\partial t}\right] d t,(6) \\
M_{i}=\int_{1 i}^{2 i}\left[a_{1} \frac{\partial M i}{\partial L i} \frac{\partial L i}{\partial t}+a_{2} \frac{\partial M i}{\partial K i} \frac{\partial K}{\partial t}+a_{3} \frac{\partial M i}{\partial T i} \frac{\partial T i}{\partial t}\right] d t .(7)
\end{gathered}
$$

Having decided that $M_{1} i(t)=\partial M i / \partial t=0$ and $M_{2} i(t)=\partial M i / \partial t=0$ relativelyMi, we get $M_{1 i}{ }^{*}$ and $M_{2 i}{ }^{*}$, with $\partial^{2} M_{1 i}^{*} / \partial t^{2}>0, \partial^{2} M \frac{*}{2 i} / \partial t^{2 L O}$, the values of which are beyond the monetary supply of the value range.

After substituting $\partial r i / d t=\left(\partial r_{i} / d y_{i}\right) \cdot\left(d y_{i} / \partial t\right)$ for all elements of the conversion function $M i(t)$, we get the following expression:

$$
\frac{d M i}{d y}=a_{1} \frac{\partial M i}{\partial L i} \frac{d L i}{\partial y_{1}}+a_{2} \frac{\partial M i}{\partial K i} \frac{\partial K i}{\partial y_{i}}+a_{3} \frac{\partial M i}{\partial T i} \frac{\partial T i}{\partial y_{i}} .
$$

For a specific company within a time interval $\left(t_{1} ; t_{2}\right)$ cash flow changes can be represented as follows:

$$
M_{i}\left(t_{2}\right)-M_{i}\left(t_{1}\right)=\sum_{j=1}^{n}\left[P_{i j}\left(t_{2}\right) y_{i j}\left(t_{2}\right)-P_{i j}\left(t_{i}\right) y_{i j}\left(t_{1}\right)\right] \text {, }
$$

$n$ - number of products sold over a period of time $t_{1} ; t_{2}$;

$P_{i j}$ - selling price;

$y_{i j}$ - sales volumes of $j$-th products.

With sufficient approximation, the current value of the function will be:

$$
\begin{aligned}
& M_{i}^{T}(t)=\sum_{j=1}^{n} P i j(t) y_{i j}(t), \\
& -\frac{\partial M_{i}^{12}}{\partial y_{i_{1}}}=\sum\left[P i j\left(t_{2}\right) y_{i j}\left(t_{2}\right)-P i j\left(t_{1}\right) y_{i j}\left(t_{1}\right)\right] .
\end{aligned}
$$

Formula will calculate the parameters that characterize the feasibility of introducing transformations for reform:

$$
T R_{i}(t)=\sum_{j=1}^{n}\left[\Pi P y\left(t_{2}\right) y_{i j}\left(t_{2}\right)-\Pi P_{i j}\left(t_{1}\right) y_{i j}\left(t_{1}\right)\right] / M_{i}^{T}(t)
$$

Further investigation of the obtained functionals at the extremum, and applying the Lagrange method, theoretically establishes the limits of the monetary provision of the value range for each enterprise.

Increasing disorganization can reach the threshold that can lead to irreversible negative consequences. These consequences may make it impossible to maintain 
a manageable enterprise. The onset of such an event will, on the one hand, lead to an objective and irreversible complication of the enterprise, stimulate "creative efforts, provide the impetus for internal restructuring, the discovery of new resources, the establishment of new connections for this purpose" (Sukharev, 2002).

On the other hand, if the level of organizational reproductive reflection within the timeframe specified by the event is insufficient to compensate for the extent of disorganization, negative consequences can occur, up to termination of activity. In our opinion, for such a situation it is necessary to introduce the concept of enterprise sensory threshold. It can be interpreted as the threshold value of an external (and / or internal) disturbing effect on an entity that triggers a response. We believe that the theory of the enterprise should distinguish between the sensory threshold of the enterprise as the lower limit of sensitivity of the enterprise and the threshold of reaction as an array of individual events, the occurrence of which requires an appropriate response - the sensitivity indicator.

Accurately measuring the thresholds of the sensory system will require comparing the thresholds of a number of reactions and taking into account the conditions under which this sensitivity was measured. In our opinion, the thresholds of sensitivity are personalized concerning the parameters of each enterprise (operating indicators as empirical values that can characterize its functionality).

Movement of the enterprise within the range of values and variability of the range limits is ensured by the management system based on the capabilities of the particular business entity. However, the behavior of an enterprise can be complicated by increasing imbalances, which will lead to a rapid loss of development reserves and, as a consequence, degradation of the entire potential of the enterprise. At this stage, labor productivity is significantly reduced as well as effectiveness of managing individual subsystems, insolvency increases, the aging of fixed assets and human capital is accelerated. The enterprise is on the verge of general macrodysfunction. Indicators calculated as follows can be used to determine the feasibility of a management system intervention to implement reform measures:

$$
\frac{d y_{i}}{d t}=F_{i}(y)-T R_{i}(t) \text {, }
$$

$F_{i}(y)$ - function of enterprise behavior utility;

$T R_{i}(t)$ - reform function, proportional to the volume of labor costs per unit of output and the volume of sales (table 1).

Initiative reform is objectively necessary only from stage $B$, since there are primary symptoms of existing trends of micro-dysfunction transition within the enterprise to macro-dysfunction. For stage $C$, reform is not an initiative of the management system but is driven by the influence of external institutions and cannot be considered as a planned strategy. The goals are discredited and the pace of development decreases, the real monetary security of the potential decreases, the costs of reproducing the lost positions are objectively increasing, and the resistance to internal and external entropy is reduced (Nazarova et al., 2019). On stage $D$, reform is, in fact, the only means of preventing the transformation of potential component microdysfunctions into general enterprise macro-dysfunction.

\section{Conclusions}

Increasing relationships inside and outside the enterprise expand its freedom and capabilities. As a consequence, the likelihood of the organizational behavior nature increases, which naturally increases its entropy. Thus, there is an increase in "substance of the enterprise," composed of a new nature elements. It is increasingly challenging for executives and managers to orient under such conditions: there are tendencies for disorganization and decrease (or, even, loss of controllability).

Organizational mechanism is an extremely complex system that involves several groups of relationships, a source of institutional content for the enterprise, a set of relatively stable norms, traditions, and behaviors that are unique to it. For enterprise it characterizes the expedient set of relationships within the production

Table 1

Enterprise reform indicators

\begin{tabular}{|c|c|c|c|}
\hline $\begin{array}{l}\text { Stage } \\
\text { of life }\end{array}$ & $\begin{array}{c}\text { Absolute value of } \\
\text { development potential }\end{array}$ & Variability (Indicators) & Level of dysfunction \\
\hline A & $\Pi P_{i j}^{t}>0$ & $\frac{d \Pi P_{i j}^{t}}{d t}>0$ & $\begin{array}{l}\text { Enterprise is developing with a minimal number of potential component } \\
\text { dysfunctions that can be eliminated by operational management }\end{array}$ \\
\hline$B$ & $\Pi P_{i j}^{t}>0$ & $\frac{d \Pi P_{i j}^{t}}{d t}<0 ; \frac{d \Pi P_{i j}^{t}}{d t}=0$ & $\begin{array}{c}\text { Slowdown in growth, loss of leverage to overcome emerging dysfunction, } \\
\text { unstable equilibrium }\end{array}$ \\
\hline C & $\Pi P_{i j}^{t}<0$ & $\frac{d \Pi P_{i j}^{t}}{d t}>0$ & Sharp growth of enterprise functioning problems \\
\hline$D$ & $\Pi P_{i j}^{t}<0$ & $\frac{d \Pi P_{i j}^{t}}{d t}<0$ & $\begin{array}{l}\text { The point of no return when the number of dysfunctions becomes critical, } \\
\text { which causes macro-dysfunction }\end{array}$ \\
\hline
\end{tabular}


and management processes, all other phenomena implemented within production and management mechanisms. In this regard, we should focus on "a family of economic mechanisms rather than a specific mechanism." They form their unique institutional space that structures the subjects' rules of conduct, their strategies, management decisions, and performance. In general, this set of interconnections between all elements of organizational relations determines the dynamic state of the management system, which determines the degree of its mobility, susceptibility to changing conditions.

Transformation processes are associated with profound changes in the economic system, encompassing reform of not only the economic sectors as a whole but also all economic management tools, organizational forms of its implementation, production systems, and participants of these processes.

Reformation is part of a transformation process related to increasing the functionality of the economic system due to renewal of traditional socio-economic forms and development of new structures that meet the requirements of the times.

The trajectory of such a system movement is determined by achievement of a critical point that changes the quality of socio-economic formation. At the same time, the value capitalization of the enterprise should be ensured concerning consumers and other stakeholders, participants of the enterprise activity.

\section{References:}

Bessonov, V. A. (2000). About transformational structural shifts of Russian industrial production. Economic journal HSE, 4(2), 184-219.

Bilotserkivets, V. V., \& Zavgorodnya, O. O. (2009). The evolution of the methodological foundations of the study of the new economy: from stochastic perception to the algorithmization of cognition. Economic Bulletin of NSU, 4, 6-13.

Borisov, A. N. (1989). Fuzzy information processing in decision making systems. Moskow: Radio and communications.

Bukanov, H., Kolesnyk, A., Tashkinova, O., Kotlubai, V., \& Koval, V. (2019). Social marketing in public administration of social service institutions. Revista Genero \& Direito, 8(6), 457-468.

Dosi, J., \& Winter, S. (2003). Interpretation of economic change: evolution, structures and games. 5th Intern. Symposium on Evolutionary Economics. Pushchino.

Eliseeva, I. I., \& Dmitriev, A. L (2003). Meetings with Nobel Laureates in Economics J. Heckman and L. Klein. Questions of statistics, 3, 135-148.

Gontareva, I. (1975). Mathematics and cybernetics in economics: a dictionary. Moskow: Economics.

Hurwicz, L. (1996). Institutions as families of game forms. The Japanese Economic review, 47(1), 89-96.

Izmalkov, S., Sonin, K., \& Yudkevich, M. (2008). Theory of economic mechanisms (Nobel Prize in Economics in 2007). Problems of Economics, 1, 148-157.

Kleiner, G. (2002). Systemic paradigm and enterprise theory. Issues of Economics, 10, 47-69.

Kleiner, G. (2003). From enterprise theory to the theory of strategic management. Russian journal management, 1, 31-56. Koval, V., Duginets, G., Plekhanova, O., Antonov, A., \& Petrova, M. (2019). On the supranational and national level of global value chain management. Entrepreneurship and Sustainability Issues, 6(4), 1922-1937. doi: 10.9770/ jesi.2019.6.4(27)

Koval, V., Slobodianiuk, O., \& Yankovyi, V. (2018). Production forecasting and evaluation of investments using Allen two-factor production function. Baltic Journal of Economic Studies, 4(1), 219-226. doi: 10.30525/22560742/2018-4-1-219-226

Nazarova, K., Hordopolov, V., Kopotiienko, T., Miniailo, V., Koval, V., \& Diachenko, Y. (2019). Audit in the state economic security system. Management Theory and Studies for Rural Business and Infrastructure Development, 41(3), 419-430.

Prigogin, A.I. (2007). Disorganization: causes, types, overcoming. Moskow: Alpina Business Books.

Rakhaev, B. M. (2006). Regular Chances of Economic Growth. Economic Bulletin of Rostov State University, 1(4), 156-167.

Rakhaev, B. M., Karchaeva, B. M., Kudalieva, L. M., \& Tramova, M. Sh. (2006). Regular Chances of Economic Growth. Economic Bulletin of Rostov State University, 1(4), 106-115.

Reut, D. V. (2003). The discourse of creativity and cognitive parallax. Moscow: Institute of Management Problems RAS. Ruegg-Sturm, J. (1998). New system theory and internal changes. Problems of theory and practice of management, 5, 106-111. Ruley, E. (1998). Politics of the enterprise. Problems of theory and practice of management, 4, 99-103.

Shumska, S. S. (2007). Production function in economic analysis: theory and practice of use. Economy and forecasting, 2, 138-153.

Sukharev, O. (2002). The concept of economic dysfunction and the evolution of the company. Problems of Economics, 10, 70-81.

Tereshchenko, A. N. (2008). Evaluation of the organizational and economic mechanism of the efficiency of agricultural enterprises. Economics and mathematical methods, 1, 132-143. 